\title{
Calcaneal Osteochondroma an Atypical Localization
}

\author{
Kunal Champaneri ${ }^{1}$, Vikas Dagar ${ }^{2}$ \\ ${ }^{I}$ (Senior resident Department Of Orthopaedics, ESI Rohini hospital, Delhi, India) \\ ${ }^{2}$ (IMO Department Of Pathology ESI Rohini hospital, Delhi, India)
}

\begin{abstract}
:
Objective: study of calcaneal osteochondroma which is extremely rare, less than $1 \%$ osteochondromas arise from tarsal bone.

Case report:-We are reporting a case of osteochondroma of calcaneum in a 33years old male who presented with chief complaints of mass over left heel and difficulty in walking from two years. The patient had traumatic injury two years back over left heel and after that he noticed swelling which was gradually increasing in size. There was no history of fever and spontaneous regression during the entire period of presentation. On clinical examination he was found to have swelling over calcaneal bone. On radiographic evalution an irregular, sessile, lytic mass which arose from calcaneum. The patient was offered surgery in view of duration and severity of his symptoms. On histopathological examination on gross it was $8 x 6 \mathrm{~cm}$ in size with $0.5 \mathrm{~cm}$ smooth cartilage cap over it and microscopically it is diagnosed as osteochondroma.

Conclusion:-Osteohondromas of the skeleton are common in age group of 30 years but osteochondromas which involve calcaneum are relatively rare presentation. Cartilage cap thickness greater than $1-2 \mathrm{~cm}$ in adults suggests malignant transformation. It is therefore necessary to manage these lesions through an appropriate ,surgical, timely intervention, to prevent malignant transformation.
\end{abstract}

Keywords: Calcaneum and Osteochondroma

\section{Introduction}

Osteochondroma are most common benign osseous neoplasm. Osteochondroma are seen in 2\% to $3 \%$ of general population and they represent approximately $36 \%$ to $41 \%$ of the cases with benign bone tumours ${ }^{1}$ About $60 \%$ of these occur in patients who are below 30 years of age and about $63 \%$ of the pateints are male. ${ }^{2}$ Osteochondroma or exostoses are abnormal growths of the cartilage on the surface of bone, which are inherited as an autosomal dominant trait. Some have multiple exostoses that carry a more significant risk of a malignant transformation. ${ }^{3}$ In an adult growth of an osteochondroma suggests the diagnosis of malignant transformation to a chondrosarcoma. 4 In the foot and ankle, osteochondromas are uncommon.calcaneous is one of the most unusual region for an osteochondroma.in this study we describe the clinical and radiological findings of a calcaneal osteochondroma.

\section{Case presentation}

We are reporting a case of osteochondroma of calcaneum in a 33years old male who presented with chief complaints of mass over left heel and difficulty in walking for two years. The patient had traumatic injury two years back over left heel and after that he noticed swelling which was gradually increasing in size. There was no history of fever and spontaneous regression during the entire period of presentation. On clinical examination he was found to have swelling over calcaneal bone, there was no family history of such swelling. As shown in Fig no 1, On radiographic evalution an irregular, sessile, sclerotic mass of size 9x6cm with lytic areas, which arose from calcaneum. The patient was offered surgery in view of duration and severity of his symptoms. On histopathological examination on gross it was $8 \times 6 \mathrm{~cm}$ ( shown in fig 2) in size with $0.5 \mathrm{~cm}$ smooth cartilage cap over it and microscopically it is diagnosed as osteochondroma as shown in fig no 3.

\section{Discussion}

Osteochondromas are developmental lesions rather that true neoplasm, there presentation may be solitary or as multiple lesions seen in multiple hereditary ${ }^{5}$.The most common symptom is a nontender, painless cosmetic deformity secondary to the slowly enlarging exophytic mass. Additional complications that cause symptoms include osseous deformity, fracture, vascular-nerve compression, neurologic sequelae, bursa formation, and malignant transformation. ${ }^{6,7}$ Histological examination of cartilaginous cap is suggestive of a malignant transformation, if it is more than $2 \mathrm{~cm}$ thick. Malignant transformation is seen in less than $1 \%$ to $2 \%$ of patients of solitary osteochondroma and in $5 \%-25 \%$ of patients with multiple hereditary exostoses. ${ }^{8,9} \mathrm{Clinical}$ 
features suspicious for malignant transformation comprise new onset of pain in a previously stable lesion, rapid or new growth, growth after skeletal maturity, and/or large lesions. These lesions are usually a low-grade chondrosarcoma or less often a secondary osteosarcoma. The treatment of osteochondromas is conservative or surgical (excision).Stable, small asymptomatic lesions can be treated conservatively. If the lesion is large and causes discomfort in daily activity or exhibits signs of malignant transformation should be treated surgically. A marginal resection is adequate and shows a low rate of recurrence. Any remaining cartilage cap may result in recurrence, especially in growing lesions.2The histological finding guides for assessing the risk of recurrence as recommended by Blitz et al.,in his case series. Nogier et al suggested the need of a surgical intervention (excision) for these tumours, for relief from pain.

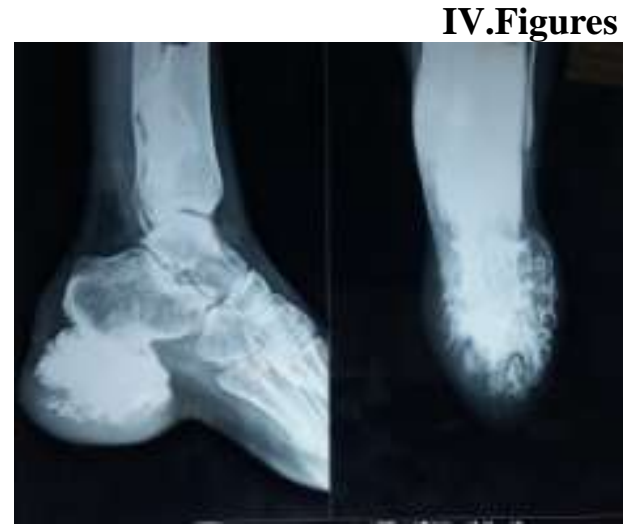

(a)

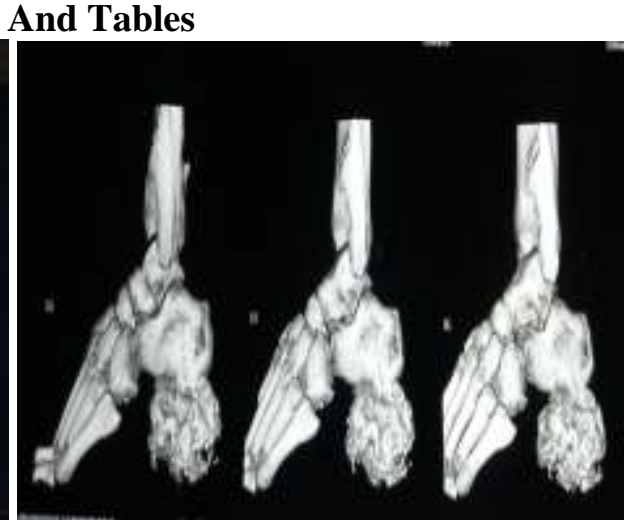

(b)

Fig 1:-Radiological picture of calcaneal growth (a) an irregular, sessile, sclerotic mass of size 9x6 $\mathrm{cm}$ with lytic areas, which arose from calcaneum (b) 3 dimentional reconstrucyion of growth on CT showing cartilage cap thickness of $0.5 \mathrm{~cm}$ surrounding sclerotic growth.

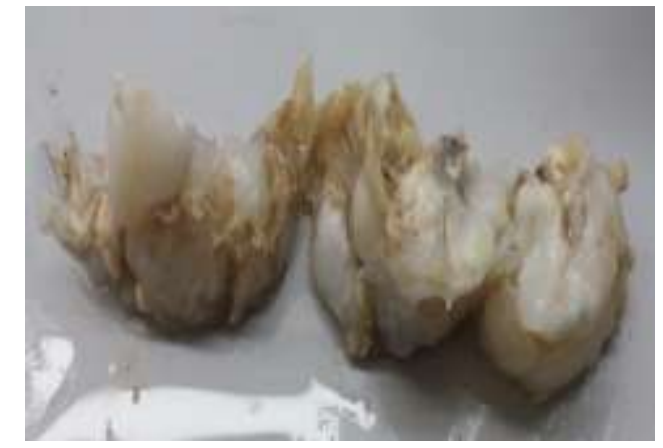

(a)

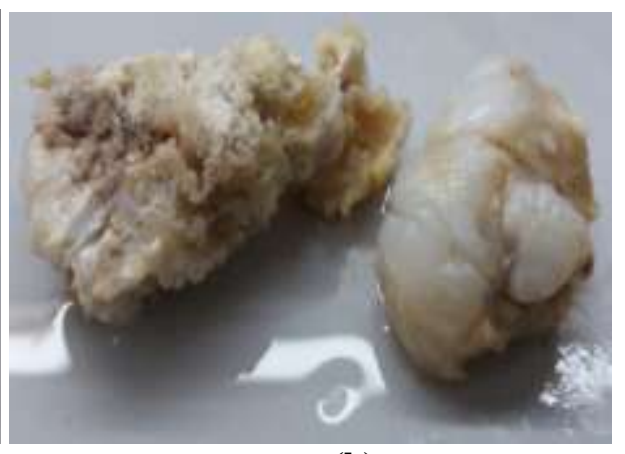

(b)

Fig 2:-Gross pictures of calcaneal growth shows whitish cartilaginous cap covering hard bone.

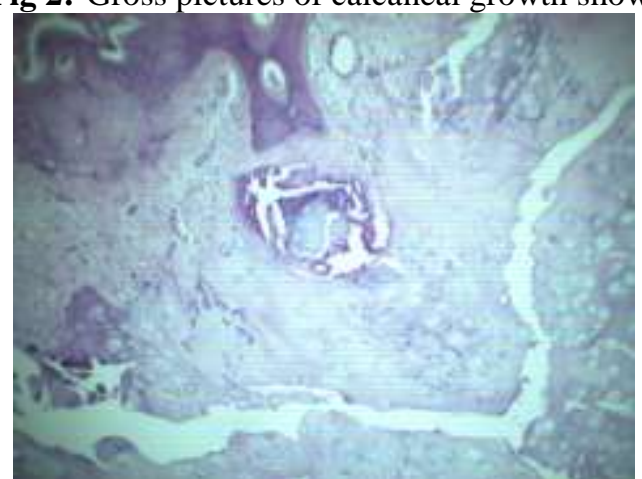

(a)

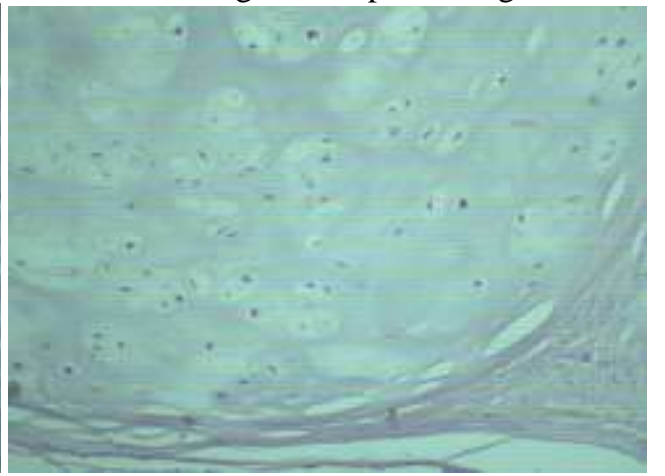

(b)

Fig 3:-Microscopic picture of calcaneal growth showing fragments of cancellous bone, with cartilaginous cap suggestive of osteochondroma. 


\section{Conclusion}

Benign osteochondromas can represent symptomatic growth in skeletally mature patients without malignant transformation and surgical excision give complete symptomatic relief .Histopathological confirmation of the lesion and aggressive search for malignant transformation zone is key to prevent recurrence.

\section{References}

[1]. Griffiths HJ, Thompson RC Jr, Galloway HR, Everson LI, Suh JS, Bursitis in association with solitary osteochondromas presenting as mass lesions Skeletal Radiol 1991 20:513-16.

[2]. Karasick D,Schweitzer ME,Eschelman DJ,Symptomatic osteochondroma:imaging feature.AJR AM J Roentgenol,1997;168:1507-12

[3]. Blitz NM, Lopez KT, Giant solitary osteochondroma of the inferior medial calcaneal tubercle: A casereport and review of the literature J Foot Ankle Surg 2008 47:206-12.

[4]. KeithA.Studies on the anatomical changes which accompany certain growth disorders of the human body.J Anat.1920;54:101-106.

[5]. Calafiora G,bertone C, Urgelli S,Rivera F,Maniscalco P,Osteochondroma: A case report with atypical localization and symptomatology. Acta Biomed AtenacParemense:2001;72:91-96

[6]. Lee JK,Yao L, Wirth Cr, MR imaging os solitary osteochondromas;report of eight cases.AJR Am J Roentgenol.1987;149;557-60

[7]. De Beuckeleer LH,De Schepper AM, Ramon F, Magnetic resources imaging of cartilaginous tumours;is it useful or necessary? Skeletal Radiol.25;137-41

[8]. (NogierA, De pinieux, G,Hottya G, Antract P. Case report enlargementof a calcaneal osteochondroma after skeletal maturity.ClinorthopRelat Res 2006;447;260-266

[9]. Karasick D,Schweiter ME,Eschelman DJ.Symptomatic osteochondromas:imaging features.AJR Am J roentgenol1997,168:1507-12

[10]. Van Lerberghe E,Van Damme B, Van Holsbleeck M,Burssens A,Hoogmartens M. Case report 626;Osteosarcoma arising in solitary osteochondroma of the femur.Skeletal Radiol 1990;19;594-97

[11]. Nojima T,Yamashiro K,Fujita M,Isu K,Ubayama Y,Yamawaki S. A case of osteochondroma arising in a solitary osteochondroma.ActaorthopScand1991;62;290-92 